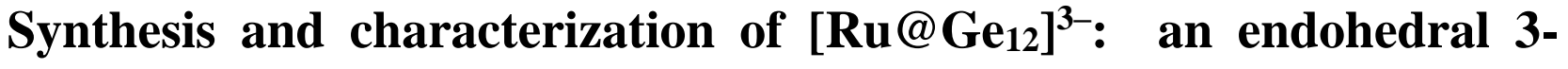

\section{connected cluster}

Gabriela Espinoza-Quintero, Jack C. A. Duckworth, William K. Myers, John E. McGrady* and Jose M. Goicoechea*

Department of Chemistry, Inorganic Chemistry Laboratory, University of Oxford, South Parks Road, Oxford, OX1 3QR, United Kingdom.

\begin{abstract}
The 12-vertex endohedral cluster $\left[\mathrm{Ru} @ \mathrm{Ge}_{12}\right]^{3-}$ reveals an unprecedented $D_{2 d-}$ symmetric 3-connected polyhedral geometry. The structure contrasts dramatically with the known deltahedral or approximately deltahedral geometries of $\left[\mathrm{M} @ \mathrm{~Pb}_{12}\right]^{2-}(\mathrm{M}=\mathrm{Ni}, \mathrm{Pd}, \mathrm{Pt})$ and $\left[\mathrm{Mn} @ \mathrm{~Pb}_{12}\right]^{3-}$, and is a result of extensive delocalization of electron density from the transition metal centre onto the cage.
\end{abstract}

The chemistry of endohedral Zintl ion clusters has been developed extensively over the past decade. ${ }^{1}$ Structurally-characterized examples from the $\left[\mathrm{M} @ \mathrm{E}_{9}\right]^{x^{-}},\left[\mathrm{M} @ \mathrm{E}_{10}\right]^{x^{-}}$and $\left[\mathrm{M} @ \mathrm{E}_{12}\right]^{x^{-}}(x=2,3)$ families are now known, ${ }^{2-11}$ as well as a number of larger clusters where two transition metal ions are encapsulated inside a main-group element cage. ${ }^{12-15}$ The vast majority of these species are diamagnetic, their properties being readily understood in terms of a structurally inert $\mathrm{d}^{10}$ transition metal atom/ion inside a closo deltahedral cage with a $4 n+2$ valence electron count. Within the 10- 
vertex family, the $\left[\mathrm{Ni} @ \mathrm{~Pb}_{10}\right]^{2-}$ cluster is a classic example, containing a formally zerovalent group 10 metal atom within a $\left[\mathrm{Pb}_{10}\right]^{2-}$ cage. ${ }^{4}$ However, the simultaneous reports of pentagonal prismatic $\left[\mathrm{Fe} @ \mathrm{Ge}_{10}\right]^{3-}$ and $\left[\mathrm{Co} @ \mathrm{Ge}_{10}\right]^{3-}$ in 2009 identified an alternative paradigm for M@E not on deltahedral motifs but rather on 3-connected architectures. ${ }^{5,6}$ In the absence of an endohedral metal, closo-deltahedral structures are characteristic of electron-deficient $(4 n+2)$ electron counts while 3-connected structures are typical of electron-precise ( $5 n)$ valence electrons. The preference for 3-connected structures in endohedral clusters of (relatively) early transition metals is therefore indicative of substantial transfer of electron density from the central metal to the $\mathrm{E}_{10}$ unit: i.e. the metal is far from inert in an electronic and structural sense. An intermediate case, $\left[\mathrm{Fe} @ \mathrm{Sn}_{10}\right]^{3-}$, where the central metal is sufficiently electron-rich to induce significant distortions to the deltahedron but not to force the transition to a 3-connected polyhedron has also been identified recently. ${ }^{7}$

Turning to the 12-vertex family, the deltahedral structural type is exemplified by 60 -electron icosahedral $\left[\mathrm{M} @ \mathrm{~Pb}_{12}\right]^{2-}(\mathrm{M}=\mathrm{Ni}, \mathrm{Pd}, \mathrm{Pt})$ and $\left[\mathrm{Ir} @ \mathrm{Sn}_{12}\right]^{3-}$, all of which can be understood as $\mathrm{d}^{10}$ metal atoms/ions inside deltahedral dianionic cages $\left(4 n+2=50\right.$ electrons). ${ }^{8-10}$ The 12 -vertex analogue of $\left[\mathrm{Fe} @ \mathrm{Sn}_{10}\right]^{3-}$ is $\left[\mathrm{Mn} @ \mathrm{~Pb}_{12}\right]^{3-}$, where the icosahedron is substantially distorted but still identifiably deltahedral. ${ }^{11}$ Conspicuously absent, however, is a 12-vertex analogue of $\left[\mathrm{Fe}_{0} \mathrm{Ge}_{10}\right]^{3-}$ and $\left[\mathrm{Co} @ \mathrm{Ge}_{10}\right]^{3-}$, where the cluster adopts an entirely 3-connected geometry. In principle, the 12vertex family offers three distinct 3-connected geometries, the hexagonal prism $\left(D_{6 h}\right)$, the $T_{d^{-}}$ symmetric truncated tetrahedron and the $D_{2 d}$-symmetric structure adopted by, the as of yet unidentified, $4^{4} \cdot 5^{4}$ isomer of octahedrane $\left(\mathrm{C}_{12} \mathrm{H}_{12}\right) \cdot{ }^{16}$ Structures of this type have been identified in a number of computational investigations of endohedral $\mathrm{M} @ \mathrm{Ge}_{12}$ clusters and also for the empty $\mathrm{Ge}_{12}$ cages themselves. ${ }^{17-22}$ For example, stable structures closely related to the hexagonal prism have

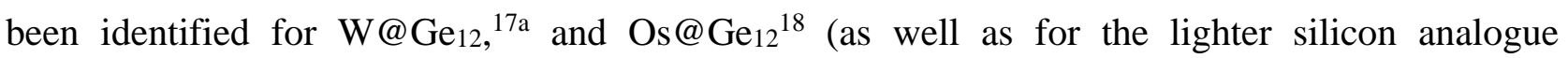


$\left.\mathrm{Cr} @ \mathrm{Si}_{12}\right) .{ }^{23}$ The $D_{2 d}$-symmetric form, in contrast, was reported to be the most stable isomer of $\mathrm{M} @ \mathrm{Ge}_{12}$ where $\mathrm{M}$ is $\mathrm{Ni},{ }^{17 \mathrm{~b}, 19} \mathrm{Cu},{ }^{20 \mathrm{a}}$ or $\mathrm{Au}{ }^{20 \mathrm{~b}} \mathrm{King}$ et al. have also identified the $D_{2 d \text {-symmetric }}$ structure as an unstable isomer on the potential energy surface of the neutral empty Ge 12 cage. ${ }^{21}$ The truncated tetrahedral structure has been discussed by Schaeffer and co-workers in the context of endohedral hydrocarbon cages. ${ }^{24}$ Our previous experience with endohedral germanium clusters suggested that one of these 3-connected structures should be accessible (albeit synthetically challenging) with electron-rich transition metals. Herein, we report the synthesis and structural

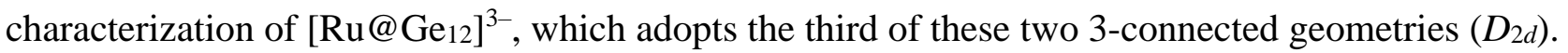
It constitutes the first example of an endohedral complex of a 12-vertex Zintl cluster based on a 3connected polyhedron, and completes the 12-vertex family. Its electronic structure also reinforces the active structural role played by the $\mathrm{d}$ orbitals of the early/mid transition metals in clusters of this type.

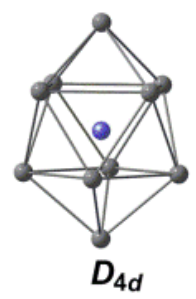

52-e [Ni@Pb $\left.{ }_{10}\right]^{2-}$

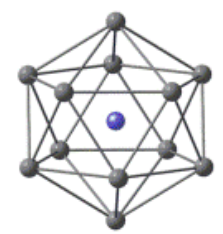

$I_{h}$

60-e $\left[\mathrm{Ni} @ \mathrm{~Pb}_{12}\right]^{2-}$

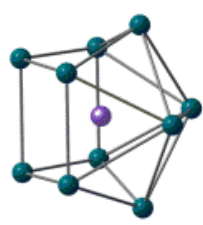

$C_{2 v}$

51-e [Fe@Sn 0$]^{3-}$

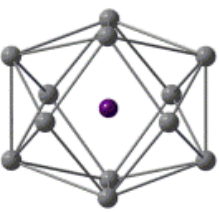

$D_{2 h}$

58-e [Mn@Pb $\left.{ }_{12}\right]^{3-}$

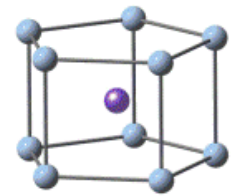

$D_{5 h}$

51-e [Fe@Ge $\left.{ }_{10}\right]^{3-}$
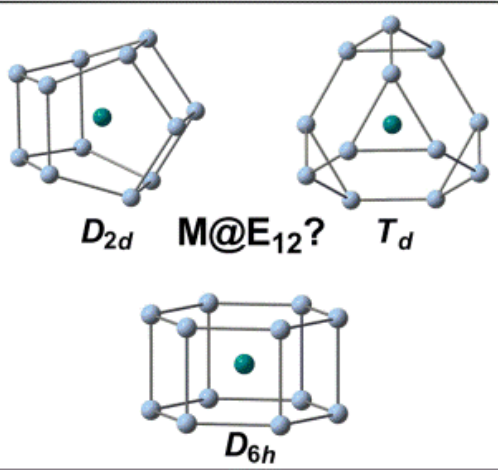

electron precise,

\section{3-connected}

electron deficient,

deltahedral intermediate

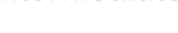


The $\left[\mathrm{Ru} @ \mathrm{Ge}_{12}\right]^{3-}$ anion was synthesized by reaction of an ethylenediamine solution of $\mathrm{K}_{4} \mathrm{Ge} 9$ with $\left[\mathrm{Ru}(\mathrm{COD})\left\{\eta^{3}-\mathrm{CH}_{3} \mathrm{C}\left(\mathrm{CH}_{2}\right)_{2}\right\}_{2}\right]\left(\mathrm{COD}=1,5\right.$-cyclooctadiene) ${ }^{25}$ Multiple reactions were monitored by electrospray ionization mass-spectrometry (ESI-MS) in an attempt to find the optimal reaction conditions. Ultimately, we found that mild heating of the reaction mixture to $65{ }^{\circ} \mathrm{C}$ improved the yield of $\left[\mathrm{Ru} @ \mathrm{Ge}_{12}\right]^{3-}$ and reduced the number of undesired side-products (specifically, eliminating the presence of $\left[\mathrm{Ge}_{9}\right]^{x^{-}}$where $x=2-4$ ). However despite these efforts, a compositionally pure sample of the cluster could not be obtained: dark greenish brown crystals of $[\mathrm{K}(2,2,2-$

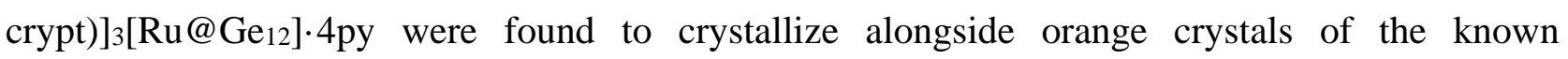
diamagnetic Zintl ion $\left[\mathrm{Ge}_{5}\right]^{2-}$ (present in ESI-MS solutions of the crude reaction mixtures) ${ }^{26}$ The different crystal morphologies and colors do, however, allow for a mechanical separation of the samples..$^{27}[\mathrm{~K}(2,2,2 \text {-crypt })]_{3}\left[\mathrm{Ru} @ \mathrm{Ge}_{12}\right] \cdot 4$ py crystallizes in space group $P 2_{1}$ (No. 4) and reveals a single crystallographically unique cluster anion in the asymmetric unit alongside three chargebalancing $[\mathrm{K}(2,2,2 \text {-crypt })]^{+}$cations and some solvent of crystallization. Despite some issues with rotational disorder at the cluster site (see Supporting Information for full details) it is apparent from the crystal structure that the anion adopts an unprecedented $D_{2 d}$ geometry reminiscent of $4^{4} .5^{4}$ octahedrane (Figure 1). Attempts to crystallize $\left[\mathrm{Ru} @ \mathrm{Ge}_{12}\right]^{3-}$ using alternative sequestering agents or solvents were unsuccessful. 


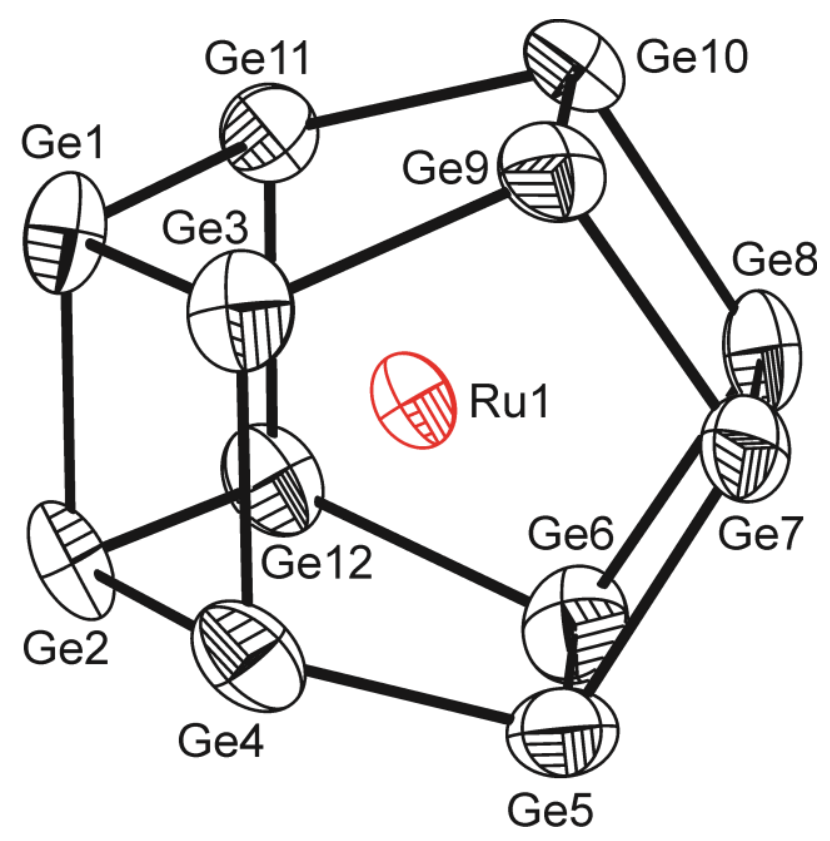

Figure 1. Molecular structure of the anionic cluster characterized in $[K(2,2,2-$ crypt) $]_{3}\left[\mathrm{Ru} @ \mathrm{Ge}_{12}\right] \cdot 4$ py (anisotropic displacement ellipsoids pictured at $50 \%$ probability level). Minor disorder component (28\% occupancy) has been removed for clarity. Selected bond distances

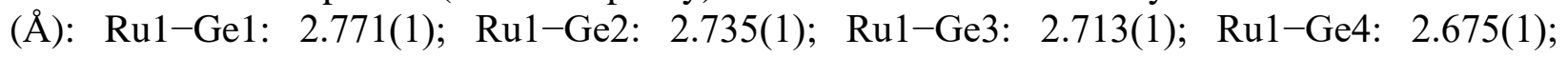
Ru1-Ge5: 2.684(1); Ru1-Ge6: 2.667(2); Ru1-Ge7: 2.725(1); Ru1-Ge8: 2.721(1); Ru1-Ge9: 2.708(1); Ru1-Ge10: 2.705(2); Ru1-Ge11: 2.714(1); Ru1-Ge12: 2.651(1); Ge1-Ge2: 2.442(2); Ge1-Ge3: 2.489(2); Ge1-Ge11: 2.489(2); Ge2-Ge4: 2.479(2); Ge2-Ge12: 2.474(2); Ge3-Ge4: 2.577(2); Ge3-Ge9: 2.466(2); Ge4-Ge5: 2.466(2); Ge5-Ge6: 2.601(2); Ge5-Ge7: 2.485(2); Ge6-Ge8: 2.478(2); Ge6-Ge12: 2.467(2); Ge7-Ge8: 2.451(2); Ge7-Ge9: 2.485(2); Ge8-Ge10: 2.487(2); Ge9-Ge10: 2.599(2); Ge10-Ge11: 2.478(2); Ge11-Ge12: 2.585(2).

The twelve vertices of the $D_{2 d}$-symmetric cage separate into two symmetry-distinct types, $\mathrm{Ge}_{\mathrm{a}}$ (Ge1-2, 7-8) and $\mathrm{Ge}_{\mathrm{b}}(\mathrm{Ge} 3-6,9-12)$ in a 4:8 ratio. Each vertex is bonded to three adjacent atoms, giving a total of 18 edges. The pseudo-spherical nature of the cluster is reflected in the narrow distribution of $\mathrm{Ru}-\mathrm{Ge}$ distances which vary between 2.651(1) and 2.771(1) $\AA$, the longest of these corresponding to the orthogonal edges linking two atoms of the $\mathrm{Ge}_{\mathrm{a}}$ set. The $\mathrm{Ge}-\mathrm{Ge}$ distances range between 2.442(2) and 2.601(2) A and are relatively short compared to the parent cluster anion (e.g. $\left[\mathrm{Ge}_{9}\right]^{3-}:$ 2.494(7)-2.713(7) $\AA$ ), ${ }^{28}$ but very similar to those reported for other three connected 
germanium clusters $\left(\left[\mathrm{Fe} @ \mathrm{Ge}_{10}\right]^{3-}: 2.526(1)-2.622(1) \AA ;\left[\mathrm{Co}_{0} @ \mathrm{Ge}_{10}\right]^{3-}: 2.502(1)-2.622(1) \AA\right)^{5,6}$ The bond lengths are also comparable to the sum of the covalent single bond radii for two germanium atoms $(2.40,2.42 \AA) .{ }^{29}$

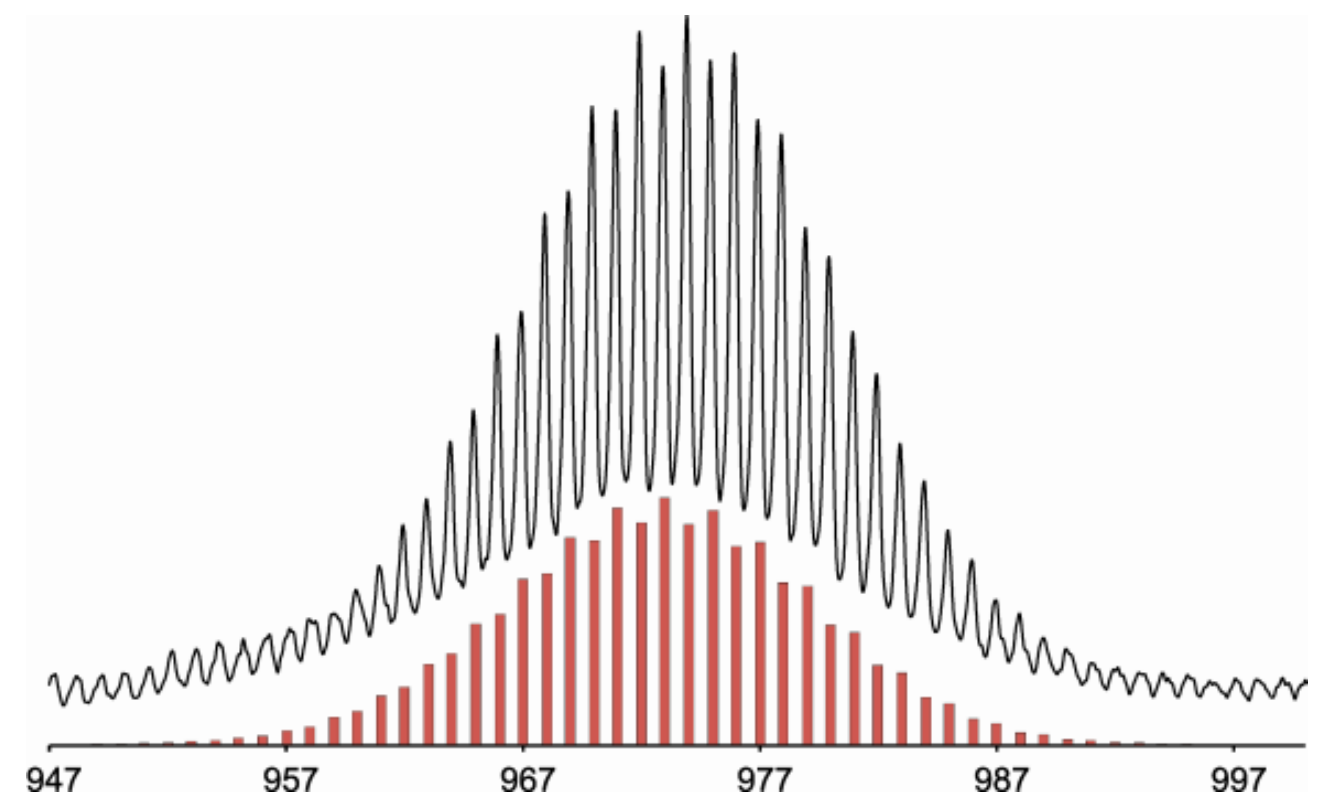

Figure 2. Negative ion-mode electrospray mass-envelope corresponding to $\left[\mathrm{Ru} @ \mathrm{Ge}_{12}\right]^{-}$. Recorded experimental data are given in black with the calculated isotopic distribution in red.

The elemental composition of the cluster anion was confirmed by ESI-MS studies on DMF solutions of the crystalline product from which $[\mathrm{K}(2,2,2-\mathrm{crypt})]_{3}\left[\mathrm{Ru}_{\mathrm{a}} \mathrm{Ge}_{12}\right] \cdot 4$ py was isolated. Cluster peaks appear as distinct mass envelopes due to the variety of naturally occurring germanium $(70,72-74$, 76) and ruthenium $(96,98-102,104)$ isotopes, which allows for the unequivocal assignment of cluster-based signals. ${ }^{[30]}$ As is often the case with the negative ion mode ESI-MS spectra of anionic Zintl ions, the clusters are observed with reduced charges as a result of the oxidation of the parent clusters during ionization/desolvation. The negative ion mode spectrum revealed mass envelopes

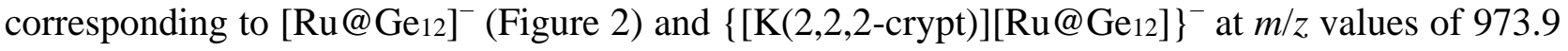


and 1389.2, respectively. Positive ion mode spectra also revealed a peak corresponding to $\{[\mathrm{K}(2,2,2-$

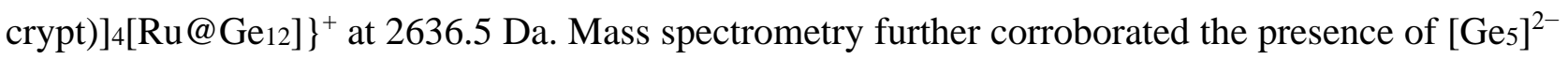
as a reaction product (-ve ion mode: $364.0\left[\mathrm{Ge}_{5}\right]^{-}, 403.4\left\{\mathrm{~K}\left[\mathrm{Ge}_{5}\right]\right\}^{-}, 779.6\left\{[\mathrm{~K}(2,2,2-\mathrm{crypt})]\left[\mathrm{Ge}_{5}\right]\right\}^{-}$ ; +ve ion mode: $\left.1609.8\left\{[\mathrm{~K}(2,2,2 \text {-crypt })]_{3}\left[\mathrm{Ge}_{5}\right]\right\}^{+}\right)$, confirming the non-stoichiometric nature of the reaction.

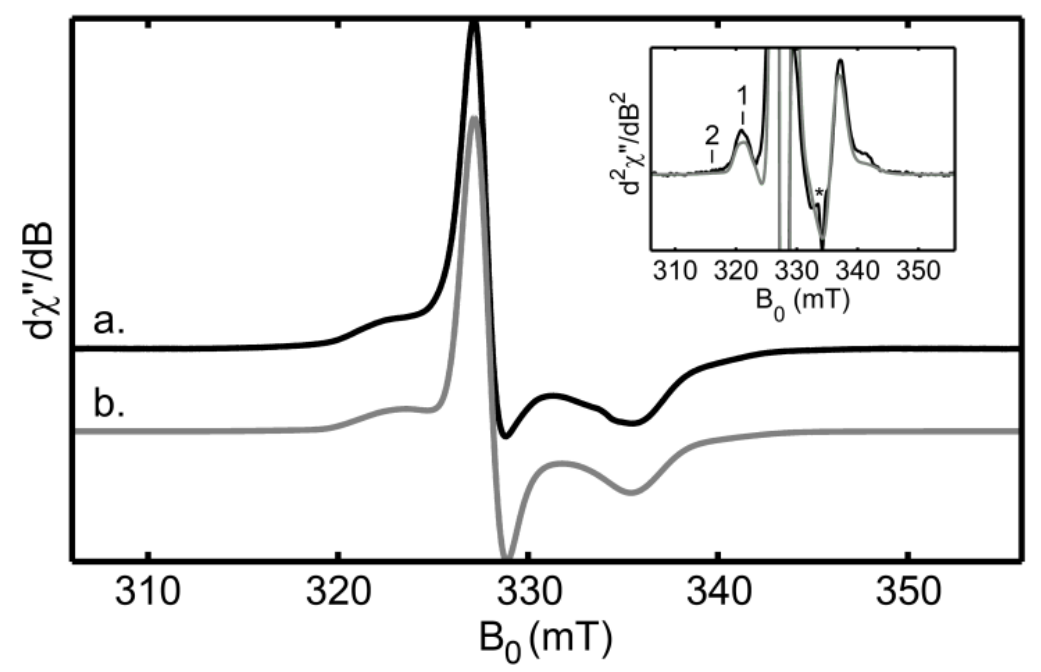

Figure 3. Experimental (a. black) and simulated (b. green) EPR spectra for $\left[\mathrm{Ru} @ \mathrm{Ge}_{12}\right]^{3-}$. The simulation uses $g_{\perp}=2.043$ and $g_{\|}=1.993$, with $A\left({ }^{73} \mathrm{Ge}_{b}\right)=33 \mathrm{MHz}$ given a Gaussian distribution of $\sigma=20 \mathrm{MHz}$. inset: second derivative of absorption by pseudo-modulation of the data and simulation, showing shoulders corresponding to a one ${ }^{73} \mathrm{Ge}(1)$ and more than one ${ }^{73} \mathrm{Ge}(2)$ located in the eight $\mathrm{Ge}_{b}$ positions. Non-saturating conditions were found at $85 \mathrm{~K}$, with a microwave frequency of $9.3691 \mathrm{GHz}$, microwave power of $10 \mu \mathrm{W}$, modulation amplitude of $0.2 \mathrm{mT}$, a time constant of $81.92 \mathrm{~ms}$, and a sweep rate of $42.94 \mathrm{~s}$ over $50 \mathrm{mT}$.

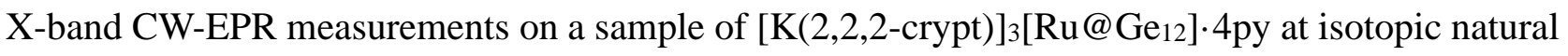
abundance in a pyridine glass confirm the paramagnetic character of the anion. The spectrum shown in Figure 3 can be simulated using axially anisotropic $g$ values $\left(g_{\|}=1.993, g_{\perp}=2.043\right)$ and an isotropic hyperfine coupling of $\left|A_{\text {iso }}\right|=33 \mathrm{MHz}$ on the eight symmetry-related $\mathrm{Ge}_{\mathrm{b}}$ atoms. 
Electronic structure. To explore the origins of the highly unusual geometry adopted by the $\left[\mathrm{Ru} @ \mathrm{Ge}_{12}\right]^{3-}$ anion, we have used density functional theory to compute the relative energies of various high-symmetry points on its doublet potential energy surface. The most stable minimum has $D_{2 d}$-symmetry and bond lengths very similar to those reported from the crystallographic experiment: $\mathrm{Ru}-\mathrm{Ge}$ and $\mathrm{Ge}-\mathrm{Ge}$ distances lie in the range $2.81-2.89$ and 2.56-2.72 $\AA$, respectively. The computed $g$ factors $\left(g_{\|}=2.000, g_{\perp}=2.023\right)$ for the $D_{2 d}$ structure are also very similar to those obtained from the simulation of the EPR data, as are the relative magnitudes of the computed isotropic hyperfine constants at $\mathrm{Ge}_{\mathrm{a}}(3 \mathrm{MHz})$ and $\mathrm{Ge}_{\mathrm{b}}(-20 \mathrm{MHz})$ : only the former can be resolved in the measured spectrum $\left(\left|A_{\text {iso }}\right|=33 \mathrm{MHz}\right)$, as detailed in the Supporting Information. The very different hyperfine coupling constants at $\mathrm{Ge}_{\mathrm{a}}$ and $\mathrm{Ge}_{\mathrm{b}}$ are at first glance surprising, given that the $2 \mathrm{a}_{2} \mathrm{SOMO}$ shown in Figure 4 is delocalized over all twelve Ge centers, giving similar spin densities at $\mathrm{Ge}_{\mathrm{a}}(0.073)$ and $\mathrm{Ge}_{\mathrm{b}}(0.098)$. However, the Gea character in the SOMO is exclusively Ge $4 p$ (by symmetry) while for Geb a substantial 4 s contribution leads to a much larger contact coupling. 


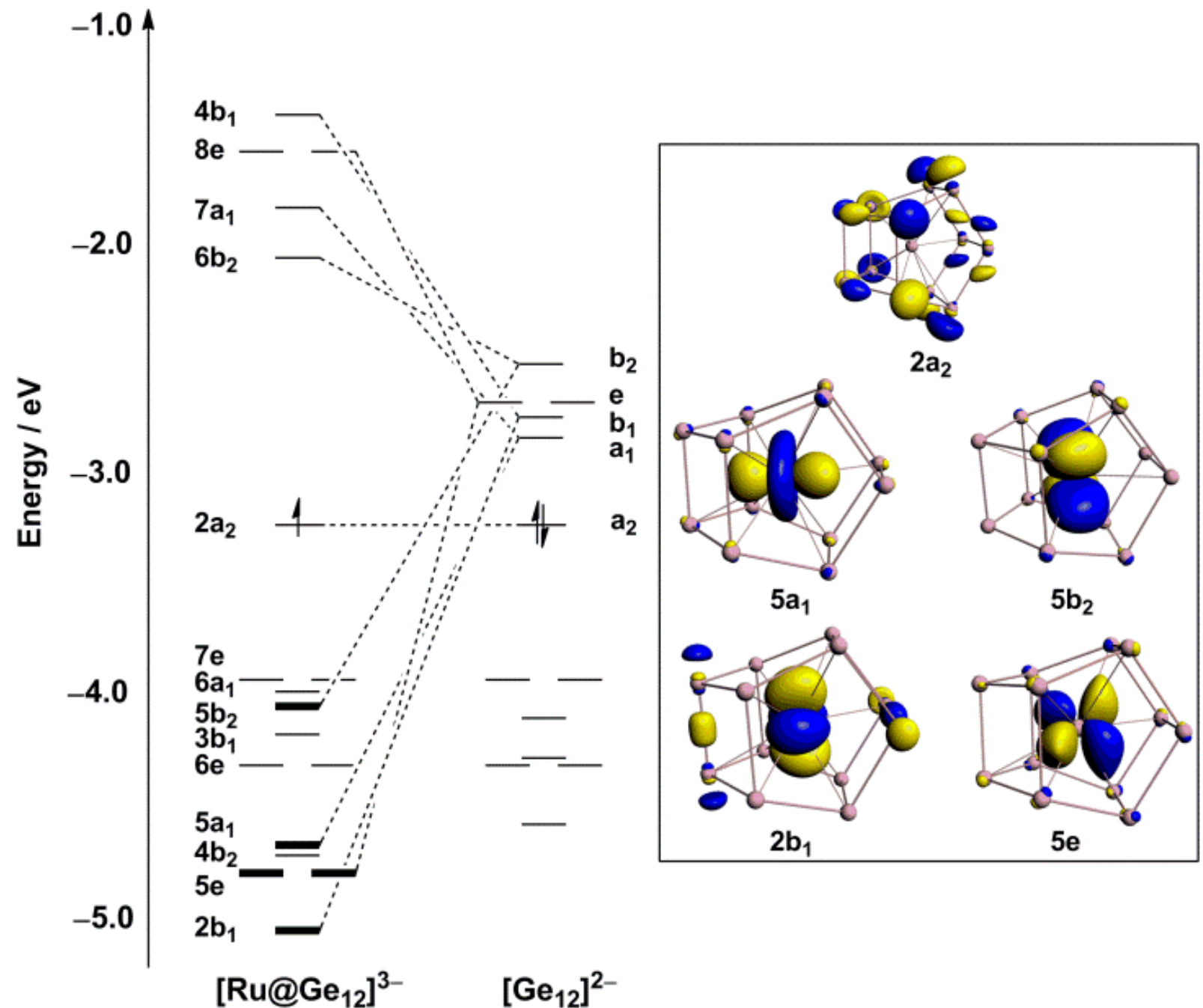

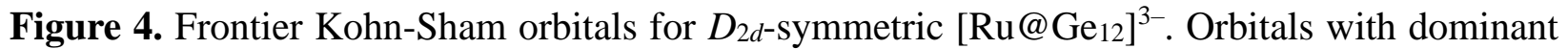
$\mathrm{Ru}$ contribution are shown in bold.

The alternative $T_{d^{-}}$and $D_{6 h}$-symmetric 3 -connected isomers proposed in Chart 1 are $5.86 \mathrm{eV}$ and $2.86 \mathrm{eV}$ less stable, respectively, than the $D_{2 d}$-symmetric minimum, and both have multiple imaginary frequencies. Amongst the approximately deltahedral structures $\left(I_{h}, D_{5 d}, D_{2 h}\right)$, the $D_{5 d}$ isomer lies lowest and is only $0.68 \mathrm{eV}$ above the equilibrium structure. This structure does not, however, correspond to a true minimum on the potential energy surface $($ nimag $=1)$, and following the imaginary frequency lies to a $D_{5 h}$-symmetric bicapped pentagonal prism at $+0.55 \mathrm{eV}$. This isomer 
is a local minimum, and has been identified in Tang et al.'s study of neutral $\mathrm{M} @ \mathrm{Ge}_{12}(\mathrm{M}=$ first row transition metal), ${ }^{22}$ but to the best of our knowledge has no precedent among structurally characterised species.

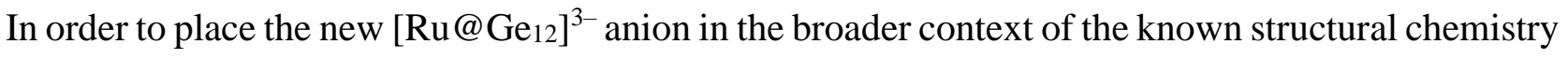
of endohedral 12-vertex clusters, we have performed a similar survey of the potential energy surface for the known deltahedral anions $\left[\mathrm{Ni} @ \mathrm{~Pb}_{12}\right]^{2-}$ and $\left[\mathrm{Mn} @ \mathrm{~Pb}_{12}\right]^{3-}$; the results are summarized in Figure 5. The horizontal axis in Figure 5 maps out a progressive destabilization of metal d orbitals $(\mathrm{Ni}<\mathrm{Mn}<\mathrm{Ru})$, and this correlates with a stabilization of the 3-connected $D_{2 d}$ isomer and, to a lesser extent, the $D_{5 h}$-symmetric bicapped pentagonal bipyramid, relative to the approximately deltahedral

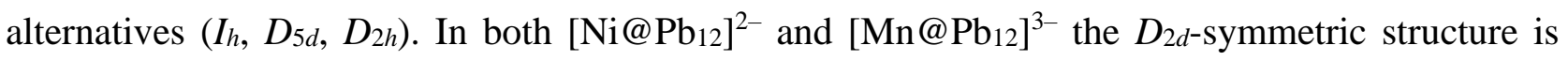
substantially less stable than either the perfect icosahedron or its $D_{5 d}$ or $D_{2 h}$-symmetric distorted variants, entirely consistent with the crystallographic evidence. The defining role of the metal $d$ orbitals in the structural chemistry is highlighted by simple electron counting principles which demand an electron-precise count (i.e. $5 \mathrm{n}=60$ valence electrons) for a 3 -connected cage. This limit can be approached only if all $8 \mathrm{~d}$ electrons on $\mathrm{Ru}$ are included in the valence electron count along with 48 from the 12 Ge centers and 3 from the charge, giving 59 in total. The single 'hole' is entirely localized on the cage ( $2 \mathrm{a}_{2}$ in Figure $\left.4, \rho\left(\mathrm{Ge}_{12}\right)=1.08\right)$, while the $\mathrm{Ru} 4 \mathrm{~d}$ character accumulates in a band of five doubly occupied orbitals, $\left\{5 \mathrm{~b}_{2}, 5 \mathrm{a}_{1}, 5 \mathrm{e}, 2 \mathrm{~b}_{1}\right\}$ with significant bonding character, some 1-2 eV below the HOMO. Conversely, the approximately deltahedral (closo) structures $\left(I_{h}, D_{5 d}, D_{2 h}\right)$ demand a $4 n+2=50$ valence electron count on the cage, which in turn requires that the metal $d$ orbitals are not included in the count (i.e. they are structurally inert). This would imply a negative formal oxidation state, $\mathrm{Ru}(-\mathrm{I})$, consistent with the relatively high Mulliken spin densities on the metal in these isomers. Of course the transition from active to inactive metal $\mathrm{d}$ orbitals is not an 
abrupt one, and the series shown in Figure 5 maps out a structural continuum from perfectly icosahedral $\left(\left[\mathrm{Ni} @ \mathrm{~Pb}_{12}\right]^{2-}\right)$ through distorted icosahedral $\left(\left[\mathrm{Mn} @ \mathrm{~Pb}_{12}\right]^{3-}\right)$ to 3-connected $\left(\left[\mathrm{Ru} @ \mathrm{Ge}_{12}\right]^{3-}\right)$.

Table 1. Optimized bond lengths and total energies (relative to $D_{2 d}$ ) of various isomers of $\left[\mathrm{Ru} @ \mathrm{Ge}_{12}\right]^{3-}$. Mulliken spin densities, $\rho$, on the Ru center and the cage are also shown, as is the number of imaginary frequencies (nimag) in each case.

\begin{tabular}{lccccccc}
\hline & $\boldsymbol{D}_{\mathbf{2} \boldsymbol{d}}$ & $\boldsymbol{D}_{\boldsymbol{6} \boldsymbol{h}}$ & $\boldsymbol{T}_{\boldsymbol{d}}$ & $\boldsymbol{D}_{\mathbf{5} \boldsymbol{h}}$ & $\boldsymbol{I}_{\boldsymbol{h}}$ & $\boldsymbol{D}_{\mathbf{5} \boldsymbol{d}}$ & $\boldsymbol{D}_{\boldsymbol{2} \boldsymbol{h}}$ \\
\hline $\mathrm{Ru}-\mathrm{G}$ & $2.81-$ & 2.91 & 3.02 & $2.78-$ & 2.76 & $2.76-$ & $2.65-$ \\
$\mathrm{e} / \AA$ & 2.89 & & & 3.13 & & 3.07 & 2.90 \\
$\mathrm{Ge}-\mathrm{G}$ & $2.56-$ & $2.56-$ & $2.52-$ & $2.70-$ & 2.91 & $2.72-$ & $2.71-$ \\
$\mathrm{e} / \AA$ & 2.72 & 2.61 & 2.62 & 3.14 & & 3.35 & 3.07 \\
$\rho(\mathrm{Ru})$ & -0.08 & 0.17 & -0.19 & 0.59 & 0.30 & 0.57 & 0.43 \\
$\rho(\mathrm{Ge} 1$ & 1.08 & 0.83 & 1.19 & 0.41 & 0.70 & 0.43 & 0.57 \\
$2)$ & & & & & & & \\
$\operatorname{nimag}$ & 0 & 6 & 12 & 0 & 5 & 1 & 1 \\
$\mathrm{E} / \mathrm{eV}$ & 0.0 & +2.86 & +5.86 & +0.55 & +1.15 & +0.68 & +0.99 \\
\hline
\end{tabular}




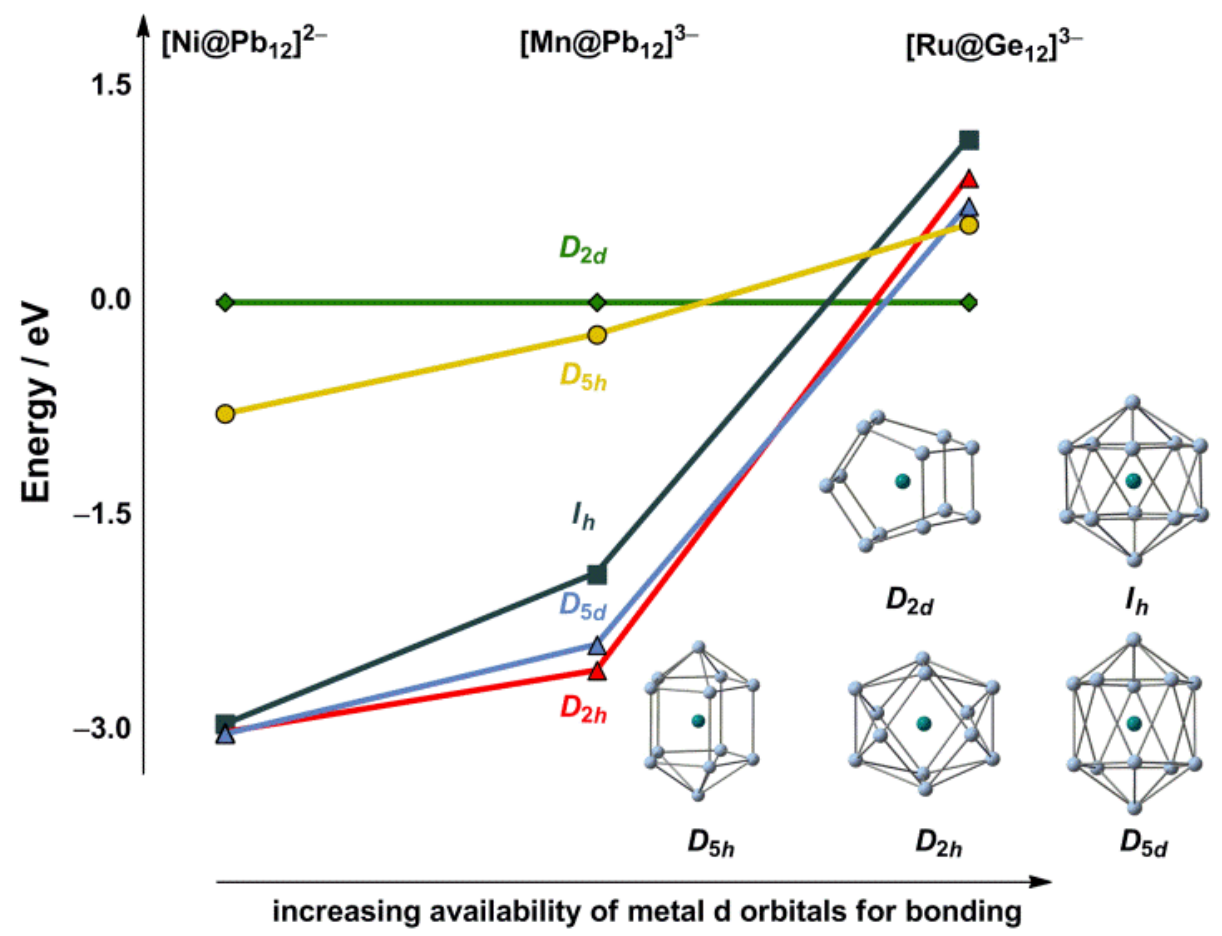

Figure 5. Relative energies of high-symmetry stationary points on the potential energy surfaces of representative members of the 12-vertex family. The $D_{2 d}$-symmetric structure is taken as the energetic reference point for each cluster.

\section{Conclusions}

In this paper we have described the synthesis and crystallographic characterization of $\left[\mathrm{Ru} @ \mathrm{Ge}_{12}\right]^{3-}$, an entirely new type of 12-vertex endohedral Zintl-ion cluster where the vertices are 3-connected. The cluster is the 12-vertex analogue of the pentagonal prismatic $\left[\mathrm{Fe} @ \mathrm{Ge}_{10}\right]^{3-}$ and $\left[\mathrm{Co} @ \mathrm{Ge}_{10}\right]^{3-}$. Density functional theory has then been used to place this new cluster in the context of the wider 12 -vertex family (including perfectly icosahedral $\left[\mathrm{Ni} @ \mathrm{~Pb}_{12}\right]^{2-}$ and the distorted but still identifiably deltahedral $D_{2 h}$-symmetric $\left.\left[\mathrm{Mn} @ \mathrm{~Pb}_{12}\right]^{3-}\right)$. The three clusters lie on a continuum defined by the electron richness of the metal: in $\left[\mathrm{Ni} @ \mathrm{~Pb}_{12}\right]^{2-}$ the $\mathrm{d}$ orbitals are lowlying and structurally inert while in $\left[\mathrm{Ru} @ \mathrm{Ge}_{12}\right]^{3-}$ all five are strongly mixed with vacant orbitals on the cluster. The 3-connected geometry characteristic of electron-precise clusters is optimal in 
this case because it allows all the five $d$ orbitals of the electron-rich metal to participate in backbonding, giving an effective $5 \mathrm{n}$ electron count at the cage.

\section{ASSOCIATED CONTENT}

\section{Supporting Information}

Full experimental details, single crystal X-ray diffraction data, ESI-MS and EPR spectra, and computational details are provided. This material is available free of charge via the Internet at http://pubs.acs.org.

\section{AUTHOR INFORMATION}

\section{Corresponding Author}

Jose M. Goicoechea: jose.goicoechea@chem.ox.ac.uk. John E. McGrady: john.mcgrady@chem.ox.ac.uk.

\section{Notes}

The authors declare no competing financial interests.

\section{ACKNOWLEDGMENT}

We thank the Mexican Consejo Nacional de Ciencia y Tecnología (CONCyT; studentship GEQ) and the University of Oxford for financial support of this research. We also thank the University of Oxford for access to OSC and CAESR facilities. Professor Paul R. Raithby (Bath) is also acknowledged for helpful discussions on the SXRD data.

\section{REFERENCES}

[1] For recent reviews see: (a) Sevov, S. C.; Goicoechea, J. M. Organometallics 2006, 25, 5678-5692. (b) Scharfe, S.; Fässler, T. F. Phil. Trans. R. Soc. A 2010, 368, 1265-1284. (c) 
Scharfe, S.; Kraus, F.; Stegmaier, S.; Schier, A.; Fässler, T. F. Angew. Chem. Int. Ed. 2011, 50, $3630-3670$.

[2] Goicoechea, J. M.; Sevov, S. C. J. Am. Chem. Soc. 2006, 128, 4155-4161.

[3] Scharfe, S.; Fässler, T. F.; Stegmaier, S.; Hoffmann, S. D.; Ruhland, K. Chem.-Eur. J. 2008, 14, 4479-4483.

[4] Esenturk, E. N.; Fettinger, J.; Eichhorn, B. Chem. Commun. 2005, 247-249.

[5] Zhou, B.; Denning, M. S.; Kays, D. L.; Goicoechea, J. M. J. Am. Chem. Soc. 2009, 131, $2802-2803$.

[6] Wang, J.-Q.; Stegmaier, S.; Fässler, T. F. Angew. Chem., Int. Ed. 2009, 48, 1998-2002.

[7] Krämer, T.; Duckworth, J. C. A.; Ingram, M. D.; Zhou, B.; McGrady, J. E.; Goicoechea, J. M. Dalton Trans. 2013, 42, 12120-12129.

[8] Esenturk, E. N.; Fettinger, J.; Lam, Y.-F.; Eichhorn, B. Angew. Chem., Int. Ed. 2004, 43, $2132-2134$.

[9] Esenturk, E. N.; Fettinger, J.; Eichhorn, B. J. Am. Chem. Soc. 2006, 128, 9178-9186.

[10] Wang, J.-Q.; Stegmaier, S.; Wahl, B.; Fässler, T. F. Chem.-Eur. J. 2010, 16, $1793-1798$.

[11] Zhou, B.; Krämer, T.; Thompson, A. L.; McGrady, J. E.; Goicoechea, J. M. Inorg. Chem. 2011, 50, 8028-8037.

[12] Goicoechea, J. M.; Sevov, S. C. Angew. Chem., Int. Ed. 2005, 44, 4026-4028.

[13] Goicoechea, J. M.; Sevov, S. C. J. Am. Chem. Soc. 2005, 127, 7676-7677.

[14] Kesanli, B.; Halsig, J. E.; Zavalij, P.; Fettinger, J. C.; Lam, Y.-F.; Eichhorn, B. W. J. Am. Chem. Soc. 2007, 129, 4567-4574.

[15] (a) Sun, Z. M.; Xiao, H.; Li, J.; Wang, L.-S. J. Am. Chem. Soc. 2007, 129, 9560-9561.

(b) Kocak, F. S.; Zavalij, P.; Lam, Y.-F.; Eichhorn, B. W. Inorg. Chem. 2008, 47, 3515-3520. 
[16] (a) McGlinchey, M. J.; Hopf, H. Beilstein J. Org. Chem. 2011, 7, 222-233. (b) Wu, H.S.; Qin, X. F.; Xu, X. H.; Jiao, H.; Schleyer, P. v. R. J. Am. Chem. Soc. 2005, 127, 2334-2338.

[17] (a) Wang, J.; Han, J.-G. J. Phys. Chem. A 2006, 110, 12670-12677. (b) Wang, J.; Han, J.-G. J. Phys. Chem. B 2006, 110, 7820-7827.

[18] Lu, J.; Nagase, S. Chem. Phys. Lett. 2003, 372, 394-398.

[19] Bandyopadhyay, D.; Sen, P. J. Phys. Chem. A, 2010 114, 1835-1842.

[20] (a) Wang, J.; Han, J.-G. J. Chem. Phys. 2005, 123, 244303. (b) Li, X.-J.; Su, K.-H. Theor. Chem. Acc. 2009, 124, 345-354.

[21] King, R. B.; Silaghi-Dumitrescu, I.; Uţă, M. M. Dalton Trans. 2007, 364-372.

[22] Tang, C.; Liu, M.; Zhu, W.; Deng, K. Comp. Theor. Chem. 2011, 969, 56-60.

[23] (a) Khanna, S. N.; Rao, B. K.; Jena, P. Phys. Rev. Lett. 2002, 89, 016803. (b) Robles, R.; Khanna, S. Phys. Rev. B. 2009, 80, 115414. (c) Zheng, W.; Nilles, J. M.; Radisic, D.; Bowen, K. H. J. Chem. Phys. 2005, 122, 071101, 1-4.

[24] Moran, D.; Woodcock, H. L.; Chen, Z.; Schaeffer III, H. F.; Schleyer, P. v. R J. Am. Chem. Soc. 2003, 115, 11442-11451.

[25] $\mathrm{K}_{4} \mathrm{Ge}_{9}(80 \mathrm{mg}, 0.1 \mathrm{mmol})$ and 2,2,2-crypt (110 mg, $\left.0.3 \mathrm{mmol}\right)$ were stirred in ethylenediamine ( $4 \mathrm{~mL}$ ) for 5 minutes giving rise to a dark brown solution. A THF ( $2 \mathrm{~mL})$ solution of $\left[\mathrm{Ru}(\mathrm{COD})\left\{\eta^{3}-\mathrm{CH}_{3} \mathrm{C}\left(\mathrm{CH}_{2}\right)_{2}\right\}_{2}\right](31 \mathrm{mg}, 0.1 \mathrm{mmol})$ was added drop-wise to the ethylenediamine solution. The mixture was stirred at $65{ }^{\circ} \mathrm{C}$ for 5 hours and filtered. All volatiles were removed under reduced pressure to leave a brown powder which was washed with THF (10 mL). The resulting solid was dissolved in pyridine $(5 \mathrm{~mL})$ and filtered into an air-tight ampoule. Slow diffusion of toluene into the pyridine solution afforded dark brown block-like crystals of $[\mathrm{K}(2,2,2 \text {-crypt })]_{3}\left[\mathrm{Ru} @ \mathrm{Ge}_{2}\right] \cdot 4$ py after two weeks. This sample crystallized alongside orange block-like crystals of $[\mathrm{K}(2,2,2 \text {-crypt })]_{2}[\mathrm{Ge} 5]$. 
[26] Campbell, J.; Schrobilgen, G. J. Inorg. Chem. 1997, 36, 4078.

[27] Crystallographic data for $[\mathrm{K}(2,2,2-\mathrm{crypt})]_{3}\left[\mathrm{Ru} @ \mathrm{Ge}_{2}\right] \cdot 4 \mathrm{py}$ : monoclinic, $P 2_{1}$ (No. 4), $a$ $=14.1424(1) \AA, b=26.0428(2) \AA, c=14.2684(1) \AA, \beta=107.754(1)^{\circ}, V=5004.88(6) \AA^{3}, Z$ $=2, T=150(2) \mathrm{K}, \rho_{\text {calc }}=1.682 \mathrm{~g} \mathrm{~cm}^{-3}, \mu=6.790 \mathrm{~mm}^{-1}, \mathrm{R} 1 / \mathrm{wR} 25.74 / 15.52 \%$ for the observed data $(\mathrm{I} \geq 2 \sigma(I)), \mathrm{R} 1 / \mathrm{wR} 26.15 / 16.21 \%$ for all the data, GOF $=1.022$.

[28] Fässler, T. F.; Hunziker, M. Inorg. Chem. 1994, 33, 5380-5381.

[29] (a) Pyykkö, P.; Atsumi, M. Chem.-Eur. J. 2009, 15, 186-197. (b) Cordero, B.; Gómez, V.; Platero-Prats, A. E.; Revés, M.; Echeverría, J.; Cremades, E.; Barragán, F.; Alvarez, S. Dalton Trans. 2008, 2832-2838.

[30] de Laeter, J. R.; Böhlke, J. K.; de Bièvre, P.; Hidaka, H.; Peiser, H. S.; Rosman, K. J. R.; Taylor, P. D. P. Pure Appl. Chem. 2003, 75, 683-800.

SYNOPSIS TOC (Word Style “SN_Synopsis_TOC”).

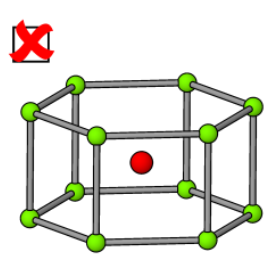

$D_{6 h}$

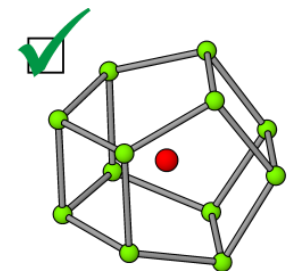

$D_{2 d}$

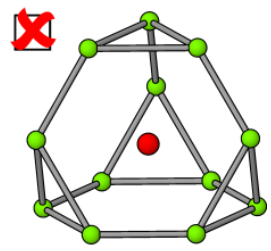

$I_{h}$ 